ROBERTO LUIZ CORCIOLI FILHO

RECRUDESCIMENTO PENAL E DISSUASÃO: UM ENSAIO COM VISTAS À SUPERAÇÃO DO MODELO NO BRASIL CONTEMPORÂNEO

DisSERTAÇÃO DE MESTRAdO

FACUldAdE DE DiReito dA UniVERSIDADE DE SÃo PAUlo

SÃo PAULO

2018 
ROBERTO LUIZ CORCIOLI FILHO

\section{RECRUDESCIMENTO PENAL E DISSUASÃO: UM ENSAIO COM VISTAS À SUPERAÇ̃̃O DO MODELO NO BRASIL CONTEMPORÂNEO}

Dissertação apresentada à Faculdade de Direito da Universidade de São Paulo como requisito parcial para a obtenção do título de mestre na área de concentração: Direito Penal, Medicina Forense e Criminologia.

FACUldAdE DE DiReito dA UnIVERSIDADE DE SÃo PAUlO

SÃo PAULO 
Catalogação da Publicação

Serviço de Biblioteca e Documentação

Faculdade de Direito da Universidade de São Paulo

Corcioli Filho, Roberto Luiz

Recrudescimento penal e dissuasão: um ensaio com vistas à superação do modelo no Brasil contemporâneo / Roberto Luiz Corcioli Filho; orientador Sérgio Salomão Shecaira - São Paulo, 2018.

133

Dissertação (Mestrado - Programa de Pós-Graduação em Direito Penal, Medicina Forense e Criminologia) - Faculdade de Direito, Universidade de São Paulo, 2018.

1. Criminologia. 2. Recrudescimento penal. 3. Neopunitivismo. 4. Dissuasão. 5. Legitimidade e justeza procedimental. I. Shecaira, Sérgio Salomão, orient. II. Título. 
Nome: Roberto Luiz Corcioli Filho.

Título: Recrudescimento penal e dissuasão: um ensaio com vistas à superação do modelo no Brasil contemporâneo.

Dissertação apresentada à Faculdade de Direito da Universidade de São Paulo como requisito parcial para a obtenção do título de mestre na área de concentração: Direito Penal, Medicina Forense e Criminologia.

Aprovada em:

Banca examinadora

Orientador Presidente: Prof. Titular Sérgio Salomão Shecaira Instituição: Faculdade de Direito da Universidade de São Paulo

$1^{\mathrm{o}}$ examinador(a):

$2^{\circ}$ examinador(a):

$3^{\text {o }}$ examinador(a): 
À Sheila e ao Benjamin, companheiros diários nas jornadas do amor.

Aos meus pais,

Solange e Roberto, com afeto. 


\section{AgRadecimentos}

Agradeço ao meu amigo e orientador Professor Titular Sérgio Salomão Shecaira, por ter me proporcionado aprofundar-me nos estudos da criminologia e, ainda, pelo apoio em tantas lutas democráticas.

Meus agradecimentos aos Professores Associados Alvino Augusto de Sá e Mariângela Gama de Magalhães Gomes pelas importantes críticas e sugestões na banca de qualificação.

À Professora Doutora Sheila Christina Neder Cerezetti, amada companheira de vida, agradeço pelo valoroso apoio (nessa e em outras frentes), pelo imprescindível incentivo acadêmico e pelas discussões especialmente a respeito da estruturação deste trabalho.

Agradeço, ainda, a colaboração de Gabriela de Oliveira Junqueira na revisão final da dissertação.

Não posso deixar de registrar meus agradecimentos ao programa de pós-graduação da FDUSP e, claro, àqueles companheiros de jornada que estiveram próximos ao longo desses três anos, pelas discussões acadêmicas, políticas, sociais, culturais, etc, pelo imprescindível incentivo para seguir adiante e pelos preciosos momentos de descontração. Gustavo, Plínio, Paula e Zé (apenas para ficar nos mais constantes), meu muito obrigado e meus votos de sucesso nas suas empreitadas acadêmicas. Aos amigos (também colegas de Arcadas) Tati e Alê, por acompanharem de perto esse humilde, mas intenso caminhar acadêmico, meu fraterno abraço.

Por fim, meus agradecimentos à minha mãe, Solange Aparecida Maia Corcioli, não apenas pela formação humana, mas também pelos votos de incentivo ao longo do caminho, e também à Christina Ribeiro Neder Cerezetti, pelo apoio acadêmico e pelo suporte com aquele que veio, neste último ano de mestrado, trazer mais luzes para nossas vidas. 


\section{RESUMO}

CORCIOLI FilHo, Roberto Luiz. Recrudescimento penal e dissuasão: um ensaio com vistas à superação do modelo no Brasil contemporâneo. 2018. 133 f. Dissertação (mestrado em Direito Penal, Medicina Forense e Criminologia) - Faculdade de Direito da Universidade de São Paulo. São Paulo, 2018.

O presente trabalho procura investigar o chamado efeito dissuasório da ameaça de reprimenda penal, inserindo-se a questão no panorama do recrudescimento punitivo experimentado desde as últimas décadas do século passado (contextualizando o fenômeno brasileiro em uma tendência neopunitivista mundial). A dissertação analisa, especialmente, estudos norte-americanos e europeus sobre o tema, contando também com o suporte da doutrina criminológica brasileira, discute os dados empíricos e resultados apresentados, adentrando na questão da criminalidade no Brasil, com a apresentação de algumas estatísticas aqui disponíveis e destacando-se a Lei de Crimes Hediondos e a atual Lei de Drogas como representantes mais significativos do punitivismo no país. Perquire-se, ainda, em que medida, de que maneira, para quais casos e em que contextos seria possível cogitarse do tal efeito dissuasório da ameaça penal, buscando-se, ao final, apresentar os elementos pelos quais se conclui pela necessidade de superação do modelo dissuasório no Brasil contemporâneo, em razão de sua inidoneidade e por não se mostrar compatível com os postulados constitucionais a serem discutidos - vislumbrando-se no horizonte de modelos alternativos a via da legitimidade e da justeza procedimental.

Palavras-chave: Recrudescimento penal. Neopunitivismo. Dissuasão. Legitimidade. Justeza procedimental. 


\begin{abstract}
CORCIOLI FilHo, Roberto Luiz. Criminal recrudescence and deterrence: an essay in favor of overcoming the model in contemporary Brazil. 2018. 133 p. Master of Laws (Criminal Law, Forensic Medicine and Criminology) - University of São Paulo Law School. São Paulo, 2018.

This research aims at exploring the so-called deterrent effect of the threat of punishment, by presenting the matter against the background of punitive recrudescence in vogue since the final decades of the last century and contextualizing the Brazilian phenomenon vis-à-vis a global new punitiveness tendency. This essay analyzes European and North-American studies on the topic (also drawing on Brazilian criminological theory), discusses the relevant empirical data and results, and touches upon the subject of criminality in Brazil, mainly by looking into some of the available statistics as well as into the Lei de Crimes Hediondos and the current Lei de Drogas as the statutes that are most representative of the punitiveness in the country. It further inquires whether and in which cases and circumstances it would be possible to sustain such a deterrent effect of the threat of punishment, intending, at the end, to present the elements that contribute to the conclusion that the deterrent model in contemporary Brazil needs to be overcome, given its unsuitability and incompatibility with constitutional principles, as well as alternative models based on legitimacy and procedural justice.
\end{abstract}

Keywords: Criminal recrudescence. New punitiviness. Deterrence. Legitimacy. Procedural justice. 
"O velho lhes deu de verdade. Marretou a latada dos coiós, tomou-lhes tufo de grana. É, seus... A coisa é ingrata. Está na alma. Na pele. Na ponta dos dedos. Não forcem a barra, que o joguinho é jogado. E o nome dele é sinuca. E não cabe na mão de um quiquiriqui qualquer. Deixem livre o campo, que a briga é maior que vocês."

ANTÔNIO, João. Bruaca. In: . Contos reunidos. São Paulo: Cosac Naify, 2012. p. 377. 


\section{SUMÁRIO}

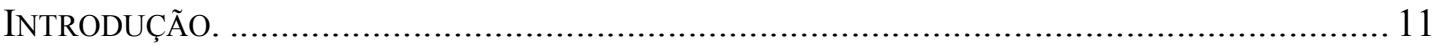

1. RECRUDESCIMENTO PENAL: NEOPUNITIVISMO E ENCARCERAMENTO EM MASSA............. 18

1.1. A emergência do Estado penal neoliberal: criminalização dos excluídos como

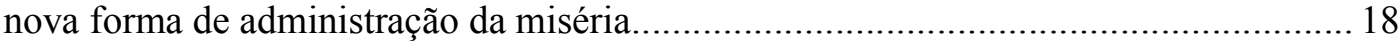

1.2. O discurso dissuasório do recrudescimento penal no Brasil: a guerra às drogas $\mathrm{e}$

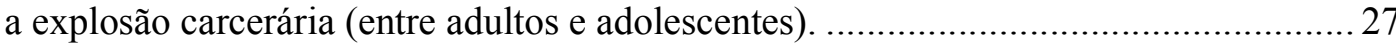

2. DISCUSSÕES ACERCA DO PODER DISSUASÓRIO DA PENA: DOS PAÍSES CENTRAIS À

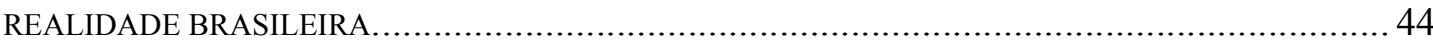

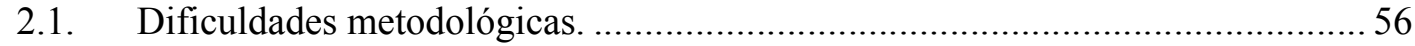

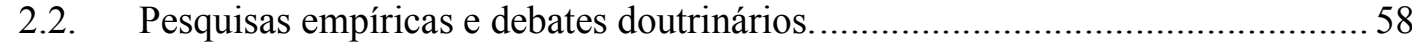

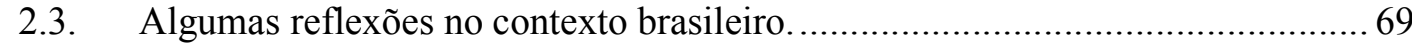

2.3.1. Reflexos sobre a Lei de Crimes Hediondos no Brasil.................................. 72

2.3.2. Recrudescimento na política criminal de drogas: alguns dados estatísticos. .. 77

2.3.3. Breves comentários a respeito do combate à corrupção como novo motor do punitivismo no Brasil.

3. RECRUDESCIMENTO PENAL COM VISTAS À DISSUASÃO: LIMITES CONSTITUCIONAIS E CUSTOS SOCIAIS. A SUPERAÇÃO DE UM MODELO FRACASSADO...................................... 85

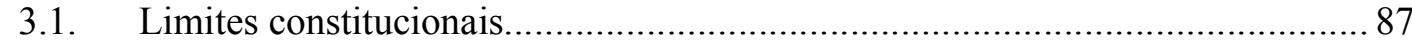

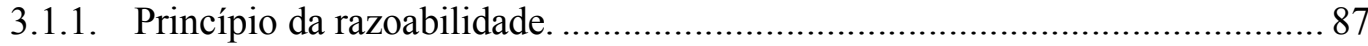

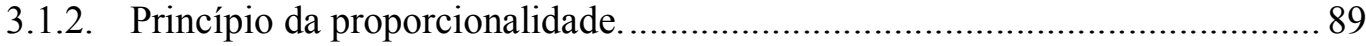

3.1.3. Princípio da humanidade da pena: vedação a penas cruéis, desumanas e

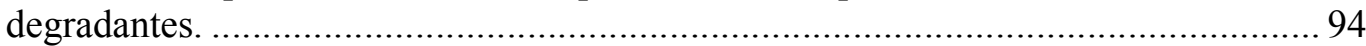

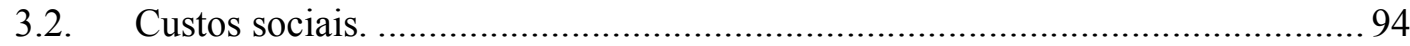

3.3. Recrudescimento penal com vistas à dissuasão: inidoneidade e ilegitimidade jurídico-social. Superando o paradigma da dissuasão com vistas ao modelo da

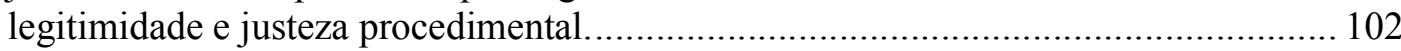

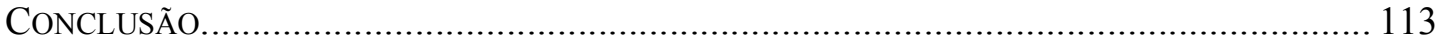

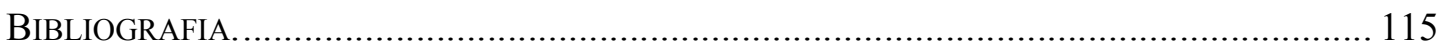

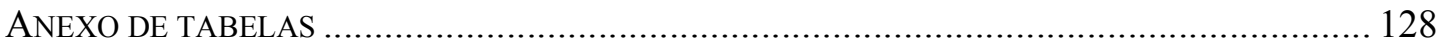




\section{INTRODUÇÃO.}

"O crime é muito e nada. Crime é um conceito livre para manobras. O desafio é entender o seu uso nos vários sistemas e, por intermédio desse entendimento, ser capaz de avaliar seu uso e quem o usa."

CHRISTIE, Nils. Uma razoável quantidade de crime. Rio de Janeiro: Revan, 2011.p. 16.

Nenhuma investigação acadêmica é isenta de espelhar em si, em alguma medida, os posicionamentos filosóficos e políticos do pesquisador, ainda que não declarados.

Não existe neutralidade em ciências sociais - jurídicas aí incluídas ${ }^{1}$. As leis não são neutras, os juízes não o são ${ }^{2}$, assim como os estudiosos. A postura político-filosófica de cada um que, à maneira de seu ofício, lida com o direito reflete diretamente nas abordagens, no raciocínio e nas decisões tomadas, seja na interpretação do ordenamento jurídico, na aplicação ou em sua discussão.

Isso não quer significar, de outro lado, que no presente trabalho (e em qualquer outro que se pretenda científico) não se almeje exercer uma postura metodológica neutra, buscando nas realidades sociológica e jurídica os elementos que se apresentem, sem um prévio direcionamento - salvo o pressuposto de pautar-se por um olhar crítico ${ }^{3}$.

Seja como for, é preciso transparência, acima de tudo, para que o leitor possa, inclusive, precaver-se em relação a eventuais posturas, mesmo que inconscientes, tendentes a direcionar as investigações à mera confirmação de um resultado já previamente almejado

\footnotetext{
${ }^{1}$ Nesse sentido, e especificamente acerca do nosso campo de interesse, vale observar com Sérgio Salomão SHECAIRA, fazendo referência a Zaffaroni, que "a criminologia enquanto práxis constitui o mais efetivo instrumento de crítica ao mito da neutralidade ideológica do Direito Penal bem como autoriza a deslegitimação da pena de prisão como instrumento principal de controle social das sociedades periféricas" (Criminologia. 2. ed. São Paulo: Revista dos Tribunais, 2008. p. 9).

${ }^{2}$ Conforme Eugenio Raúl ZAFFARONI, "o certo é que os homens têm ideologias, que não podem deixar de têlas, que os homens que se desempenham como juízes têm uma filiação política e que, ainda que privadamente, esta se expressa e se transcende, e também se expressa tanto em sua atividade extrajudicial quanto nas idéias que plasmam suas sentenças" (Poder judiciário: crise, acertos e desacertos. Tradução de Juarez Tavares. São Paulo: Revista dos Tribunais, 1995. p. 98).

${ }^{3}$ Nessa linha, confira-se OliveIRA, Luciano. Não Fale do Código de Hamurábi! A pesquisa sócio-jurídica na pós graduação em Direito. Anuário dos Cursos de Pós-Graduação em Direito (UFPE), v. 13, p. 299-330, 2003.
} 
e que, evidentemente, coaduna-se às posturas políticas, filosóficas e sociais do autor do trabalho, por exemplo ${ }^{4}$.

É preciso desde já advertir que muitos dos estudos analisados nesta pesquisa podem ser inseridos dentro da chamada Política Criminal Atuarial, na designação e definição lançadas por Maurício Stegemann DIETER ${ }^{5}$.

Por outro lado, o pensamento crítico, as ideias calcadas na criminologia crítica, e também no próprio garantismo penal ${ }^{6}$ - ciente das disputas teóricas e políticas havidas entre eles ${ }^{7}$-, servirão especialmente como referencial teórico para as críticas de legitimação das políticas de recrudescimento penal com vistas à dissuasão. E também certamente permearão todo o trabalho, por não ser viável dissociar os fundamentos e bases epistemológicas do investigador em relação ao seu campo de estudo.

\footnotetext{
${ }^{4}$ A respeito das questões ideológica e ética envolvidas na pesquisa da dissuasão penal, que incluem, por exemplo, a filiação do pesquisador a tal ou qual corrente político-filosófica e seu eventual esforço em separar sua pesquisa de suas convicções, sua crença prévia na própria justiça ou injustiça da reprimenda penal (incluída, por exemplo, a ideia de seletividade do sistema punitivo), bem como sua disposição, inclusive, em eventualmente ver seu trabalho ser tomado como suporte científico a dada política repressiva estatal, vide DiChiarA, Albert; GAlliher, John F. Thirty years of deterrence research: characteristics, causes, and consequences. Contemporary Crises, v. 8, p. 243-263, 1984. p. 255-260.

${ }^{5}$ Política criminal atuarial: a criminologia do fim da história. Rio de Janeiro: Revan, 2013. "Expressão do gerencialismo, a proposta orbita em torno do ideal de gestão eficiente da criminalidade para racionalizar a seletividade de um sistema de justiça criminal comprometido com a incapacitação mediante incorporação de instrumentos atuariais, que tornam o exercício da repressão uma rotina literalmente mecânica" (p. 267). "Em rápida síntese, entende-se por Política Criminal Atuarial o uso preferencial da lógica atuarial na fundamentação teórica e prática dos processos de criminalização secundária para fins de controle de grupos sociais considerados de alto risco ou perigosos mediante incapacitação seletiva de seus membros. O objetivo do novo modelo é gerenciar grupos, não punir indivíduos: sua finalidade não é combater o crime - embora saiba se valer dos rótulos populistas, quando necessário - mas identificar, classificar e administrar segmentos sociais indesejáveis na ordem social da maneira mais fluida possível” (p. 20).

${ }^{6}$ Aqui remete-se, evidentemente, à obra Direito e razão, de Luigi FERRAJOLI (Tradução de Ana Paula Zomer Sica; Fauzi Hassan Choukr; Juarez Tavares; Luiz Flávio Gomes. 2. ed. São Paulo: Revista dos Tribunais, 2006).

${ }^{7}$ Nessa linha, vale citar a lúcida análise de Vera Regina Pereira de ANDRADE, para quem "a oposição abolicionismo $x$ minimalismo e o correlato posicionamento a favor ou contra é equivocado e, até certo ponto, uma falsa questão" (Minimalismos, abolucionismos e eficienticismo: a crise do sistema penal entre a deslegitimação e a expansão. Revista Seqüência, n. 52, p. 163-182, jul. 2006. p. 177-178). Sustenta a autora que o garantismo está inserido em algo mais amplo, que pode ser designado como minimalismos, sendo que em seu seio há espaço para correntes (minimalismos como meios) também comprometidas com a própria razão abolicionista (e aqui ela cita Alessandro BARATTA e Eugenio Raúl ZAFFARONI). É verdade que, conforme ainda a autora, o garantismo de FERRAJOLI é tido como fim, ou seja, não tem em seu horizonte (sequer utópico) a abolição do sistema penal. Porém, sob o ponto de vista da práxis, todos os minimalismos, em conjunto com os abolicionismos, oferecem um precioso ferramental na luta pela contenção do poder punitivo e pela afirmação de direitos, inclusive com vistas a promover superações para além do sistema posto. Assim, chega a autora à conclusão de que a antítese bipolar do abolicionismo seria o eficientismo penal, inserido na lógica da política criminal atuarial, e não o garantismo penal (minimalismo). Porém, ainda com ela, não se deve perder de vista que o chamado minimalismo reformista, ao introduzir novas formas de controle e abreviar os procedimentos para a fixação da culpa, tem contribuído "para ampliar o controle social e relegitimar o sistema penal” (p. 168), ligando-se, portanto, à perspectiva do mencionado eficientismo (e também nesse sentido: KARAM, Maria Lúcia. Juizados especiais criminais: a concretização antecipada do poder de punir. São Paulo: Revista dos Tribunais, 2004. p. 23-51).
} 
Vale observar que no presente trabalho optou-se por não definir expressões ou conceitos absolutamente estabelecidos, seja porque o texto certamente não se destina a leitores que não tenham já a necessária familiaridade com eles, seja porque a pretensão pela definição de tais termos ou conceitos, ainda que "estabelecidos", pecaria pela superficialidade ou generalidade se não se dedicasse, para cada um deles, um necessário aprofundamento - o que também não se vê como adequado para os propósitos da presente dissertação.

Porém, diante da importância do pensamento criminológico crítico para a formação da base epistemológica da presente pesquisa e de todo o seu desenvolvimento, conforme se espera ser possível ao leitor conferir a seguir, não se pode deixar de pontuar, tomando-se como referência parcial as anotações de Sérgio Salomão SHECAIRA ${ }^{8}$ e valendose, ainda, da monumental narrativa da história criminológica perpetrada por Gabriel Ignacio ANITUA $^{9}$, que a teoria crítica remonta à linha de pensamento da chamada Escola de Frankfurt, com raízes marxistas, fundada na análise das inter-relações entre as formas de organização produtiva do capital e a punição criminal ${ }^{10}$.

A partir da retomada da obra de Georg RUSCHE e Otto KIRCHHEIMER ${ }^{11}$, surgiram dois grupos de criminologistas críticos, um ligado à Universidade de Berkeley (Califórnia, EUA), e outro na Inglaterra, ligado à National Deviancy Conference (tendo como um dos principais expoentes Jock YoUNG ${ }^{12}$ ). E ao lado de tais grupos, cabe mencionar, ainda, a vertente abolicionista, de origem escandinava ${ }^{13}$, sendo que todas essas correntes acabaram irradiando suas influências mundialmente, observando-se produções de viés crítico criminológico, desde a década de 1970 até os dias de hoje, em pensadores (citados a seguir apenas exemplificativamente) como o francês Michael FOUCAULT ${ }^{14}$, o também francês,

\footnotetext{
${ }^{8}$ Criminologia. 2. ed. São Paulo: Revista dos Tribunais, 2008. p. 322-325.

${ }^{9}$ Histórias dos pensamentos criminológicos. Tradução de Sérgio Lamarão. Rio de Janeiro: ICC/Revan, 2008. p. 569-760.

${ }^{10}$ De fato, segundo Sérgio Salomão SHECAIRA, “o centro das atenções do marxismo em relação à criminalidade é o seu caráter de crítica ao funcionalismo do pensamento criminal. A lei penal nada mais é do que uma estrutura (também designada superestrutura) dependente do sistema de produção (infra-estrutura ou base econômica). O direito, ao contrário do que afirmam os funcionalistas, não é uma ciência, mas sim uma ideologia que só será entendida mediante uma análise sistêmica denominada método histórico-dialético" (Criminologia. 2. ed. São Paulo: Revista dos Tribunais, 2008. p. 326).

${ }^{11}$ Punição e estrutura social. Tradução de Gizlene Neder. 2. ed. Rio de Janeiro: ICC/Revan, 2004.

${ }^{12}$ A sociedade excludente: exclusão social, criminalidade e diferença da modernidade recente. Tradução de Renato Aguiar. Rio de Janeiro: ICC/Revan, 2002.

${ }_{13}$ Cabendo citar, apenas como exemplo, CHRISTIE, Nils. Uma razoável quantidade de crime. Tradução de André Nascimento. Rio de Janeiro: ICC/Revan, 2011.

${ }^{14}$ Vigiar e punir. Tradução de Raquel Ramalhete. 40. ed. Petrópolis: Vozes, 2012.
} 
radicado nos EUA, Loïc WACQUANT ${ }^{15}$, os italianos Dario MELossi e Massimo PAVARINI ${ }^{16}$, e Alessandro BARATTA ${ }^{17}$, o escocês, radicado no EUA, David GARLAND ${ }^{18}$, e, na América Latina, a venezuelana Lola Aniyar de CASTRO ${ }^{19}$, o argentino Eugenio Raúl ZAFFARONI ${ }^{20}$, e, entre nós, vale destacar Juarez Cirino dos SANTOS ${ }^{21}$.

Quanto à presente dissertação, há que se pontuar que as principais ideologias ligadas à punição penal se associam às ideias de retribuição, reabilitação, dissuasão e incapacitação ${ }^{22}$.

Para o que interessa a este trabalho, vale apontar que a questão da dissuasão penal se insere em um panorama mais amplo relativo aos mecanismos de controle social. E ao lado da dissuasão prometida pela ameaça legal de aplicação da pena, há, ainda, a própria internalização das normas pelos indivíduos, que os fazem aderir ao ordenamento por acreditarem ser a coisa certa a fazer (podendo agir aqui, também, o receio de experimentar um sentimento de culpa por incorrer em uma conduta errada), bem como o controle informal exercido pelos demais membros da sociedade (vizinhos, colegas de trabalho, etc), inclusive por meio das instituições sociais (igreja, associações as quais o sujeito participe, a empresa ou o órgão em que trabalha, etc), de modo que em muitas situações o indivíduo procura evitar justamente o estigma e as demais consequências sociais de ser tomado como um infrator por seus pares ${ }^{23}$.

${ }^{15}$ As prisões da miséria. Tradução de André Telles. 2. ed. Rio de Janeiro: Zahar, 2011.

${ }^{16}$ Cárcere e fábrica: as origens do sistema penitenciário (século XVI-XIX). Tradução de Sérgio Lamarão. 2. ed. Rio de Janeiro: ICC/Revan, 2010.

${ }^{17}$ Criminologia crítica e crítica do direito penal: introdução à sociologia do direito penal. Tradução de Juarez Cirino dos Santos. 6. ed. Rio de Janeiro: ICC/Revan, 2011.

${ }^{18}$ A cultura do controle: crime e ordem social na sociedade contemporânea. Tradução de André Nascimento. Rio de Janeiro: ICC/Revan, 2008.

${ }^{19}$ Criminologia da reação social. Tradução e acréscimos de Ester Kosovski. Rio de Janeiro: Forense, 1983; Criminologia da libertação. Tradução de Sylvia Moretzsohn. Rio de Janeiro: ICC/Revan, 2005.

${ }^{20}$ O inimigo no direito penal. Tradução de Sérgio Lamarão. 2. ed. Rio de Janeiro: ICC/Revan, 2007.

${ }^{21}$ A criminologia radical. Rio de Janeiro: Forense, 1981.

${ }^{22}$ JiANG, Shanhe; LAMBERT, Eric G.; WANG, Jin. Capital punishment views in China and the United States. International Journal of Offender Therapy and Comparative Criminology, v. 51, n. 1, p. 84-97, 2007. p. 85.

${ }_{23}$ Nesse sentido, vide Homel, Ross. Policing and punishing the drinking driver - A study of general and specific deterrence. New York: Springer, 1988. p. 29. Também nesta linha, vide Johannes ANDENAES, para quem, inclusive, o mecanismo formal de controle seria muitas vezes a própria base da reprovação social em relação à conduta criminosa de dado indivíduo, pois a prisão, a acusação e o processo criminal o exporiam à censura comunitária (The general preventive effects of punishment. University of Pennsylvania Law Review, v. 114, n. 7, p.949-983, 1966. p. 961). 
A ideia de dissuasão através da ameaça penal remonta a Cesare Beccaria (1766), Jeremy Bentham (1823) e Johann Anselm Feuerbach (1799), tendo sido mais recentemente alvo de atenção por parte de Gary S. Becker (1968) e Issac Ehrlich $(1973)^{24}$.

Ainda que se procure elaborar explicações e justificativas à punição penal que fujam do propósito declarado de prevenção ${ }^{25}$, fato é que em última análise não se chega a outro desiderato senão a pretensão de, com a punição ou com sua ameaça, evitar-se a ocorrência de novas condutas.

Dizer que se prevê a sanção como forma de reafirmar o direito é deter-se no meio do raciocínio. Completá-lo é chegar à ideia de que a tal reafirmação do direito tem como propósito a promessa liberal de proteger bens jurídicos. E proteger de que maneira senão com a expectativa de que a sanção (prevista ou aplicada) evitará novas infrações?

E o modelo da dissuasão, conforme André ZANETIC et a ${ }^{26}$, é justamente o que vem predominando nas políticas de segurança pública no Brasil, por meio de um policiamento ostensivo que procure ser apto a intimidar possíveis infratores e da previsão de punições muitas vezes longas e severas, que se espera serem sentidas como certas, de modo a promover o desestímulo da prática de atos desviantes, dentro de um sistema de justiça no qual a garantia de direitos pelo Judiciário cede espaço ao dever de colaboração com a garantia da segurança pública.

Partindo-se de uma discussão acerca da emergência do chamado Estado Penal no último terço do século passado, expondo, brevemente, sua gênese no contexto do

\footnotetext{
${ }^{24}$ DölLING, Dieter; ENTORF, Horst; HERMANN, Dieter; RuPP, Thomas. Is deterrence effective? Results of a meta-analysis of punishment. European Journal on Criminal Policy and Research, v. 15, p.201-224, 2009.p. 201-202. Conforme, inclusive, Gary S. BECKER, "lest the reader be repelled by the apparent novelty of an 'economic' framework for illegal behavior, let him recall that two important contributors to criminology during the eighteenth and nineteenth centuries, Beccaria and Bentham, explicitly applied an economic calculus. Unfortunately, such an approach has lost favor during the last hundred years, and my efforts can be viewed as a resurrection, modernization, and thereby I hope improvement, of these much earlier pioneering studies" (Crime and punishment: an economic approach. In: BECKER, Gary S.; LANDES, William M. (eds.). Essays in the economics of crime and punishment, 1974. p. 45).

${ }^{25} \mathrm{E}$ aqui se está a centrar na investigação dos propósitos declarados da pena, deixando-se de lado a importante discussão a respeito de suas funções latentes na sociedade contemporânea - de gestão dos excluídos do mercado de produção e consumo -, posto não ser o escopo do presente estudo.

${ }^{26}$ ZANETIC, André; MANso, Bruno Paes; NATAL, Ariadne Lima; OliveIRA, Thiago Rodrigues. Legitimidade da polícia: segurança pública para além da dissuasão. Civitas, Porto Alegre, v. 16, n. 4, p. 148-173, out.-dez. 2016, p. 148 e 152. Segundo os autores, "assegurar o respeito às leis é um dos principais objetivos de todo sistema de segurança e justiça. Nas sociedades em que as leis são obedecidas há mais estabilidade, previsibilidade e segurança, beneficiando tanto aqueles que exercem autoridade, quanto a sociedade como um todo. No entanto, o respeito à lei nunca é algo garantido, de maneira que um dos desafios de qualquer estado é aumentar a disposição de seus cidadãos a respeitar as leis. Dentre os caminhos possíveis para assegurar o respeito à lei, a teoria da dissuasão tem sido tradicionalmente a principal influência para as instituições de segurança e justiça ocidentais" (Ibidem. p. 151).
} 
neoliberalismo mundial, da ampliação dos mecanismos de controle penal sobre certas parcelas da população, com especial foco na introdução do fenômeno no Brasil, será desenvolvida, no capítulo 1, uma abordagem criminológica crítica a respeito do neopunitivismo entre nós, destacando-se, no cenário brasileiro, a chamada guerra às drogas, com a consequente explosão da população carcerária nos últimos anos - inclusive no que toca à internação em massa de adolescentes, que se inserem em posição subalterna e amplamente substituível na estrutura da economia da droga.

Em seguida, iniciando-se o capítulo 2, que tratará das discussões a respeito do poder dissuasório da pena, procurar-se-á apresentar as dificuldades metodológicas para o enfrentamento do tema, especialmente em razão das inúmeras variáveis incidentes sobre o fenômeno da criminalidade.

Então, inserida em um contexto de recrudescimento penal, a presente pesquisa buscará apurar a hipótese relacionada a ser ou não tal fenômeno capaz de gerar maior efeito dissuasório (eventualmente em que medida, para quem, em quais contextos e sob quais condições). E se a priori poderia mesmo haver a tendência de se admitir que ao menos em algum nível o seja, já que, sendo racional o ser humano e almejando maximizar seu bem$\operatorname{estar}^{27}$, seria de se esperar que, no geral, o indivíduo procure evitar sofrer dado mal de maior intensidade (que vai desde o mero constrangimento do processo e da condenação para muitos, até a efetiva aflição ínsita à pena) do que aqueles possíveis benefícios vislumbrados com a prática delitiva, de outro lado também não se pode ignorar hipóteses outras, tais como a questão da adesão de certos sujeitos a determinadas subculturas criminais, ou mesmo as situações nas quais a punição seja algo visado inconscientemente em razão de certos conflitos psíquicos ${ }^{28}$.

Nesse âmbito, serão desenvolvidas algumas reflexões no contexto brasileiro, com destaque à Lei de Crimes Hediondos e ao recrudescimento na política de drogas, bem como se apontando a questão do combate à corrupção como novo motor do punitivismo no Brasil.

\footnotetext{
${ }^{27}$ Para uma breve abordagem acerca da forte influência do utilitarismo filosófico no campo jurídico, inclusive sobre a teoria da pena, vide PoSNER, Richard A. A economia da justiça. Tradução de Evandro Ferreira e Silva. São Paulo: WMF Martins Fontes, 2010. p. 60-62. Para uma abordagem sob a ótica da análise econômica do direito no campo penal de sociedades primitivas, contendo indicativos de como essa análise poderia ser aplicada na contemporaneidade, vide a mesma obra p. 242-270.

${ }^{28}$ FREUD, Sigmund. Criminoso em conseqüência de um sentimento de culpa. In: A história do movimento psicanalítico. Artigos sobre metapsicologia e outros trabalhos. Volume XIV das obras psicológicas completas do autor. Tradução sob a direção-geral de Jayme Salomão. Rio de Janeiro: Imago, 1974. p. 375-377.
} 
E importa já apontar que, no fundo, parece haver muito de crença e ideologia por traz das opiniões a respeito do poder dissuasório da ameaça penal - muito mais do que ciência baseada em evidências ${ }^{29}$.

Será, ainda, objeto de análise, já no capítulo 3, a questão da própria legitimidade de um modelo de recrudescimento com vistas à dissuasão, incursionando nos limites constitucionais que se colocam frente a tal política (com a abordagem dos princípios da razoabilidade, da proporcionalidade e da humanidade da pena) e enfrentando a questão dos próprios custos sociais envolvidos em sua implementação.

Com isso, espera-se apontar para a superação de um modelo que se demonstrará ser fracassado aos fins a que declaradamente se propõe - e que sequer encontra respaldo na ordem constitucional brasileira -, direcionando, então, os olhares à alternativa apresentada pelo chamado modelo da legitimidade e justeza procedimental ${ }^{30}$.

${ }^{29}$ TONRY, Michael. Less imprisonment is no doubt a good thing - more policing is not. Criminology \& Public Policy, v. 10, n. 1, p. 137-152, 2011. p. 148.

${ }^{30}$ Como alternativas ao modelo da dissuasão, Tom R. TYLER menciona o modelo calcado na legitimidade e na justeza procedimental, bem como as práticas de justiça restaurativa e o chamado policiamento comunitário (Procedural justice, legitimacy and the effective rule of law. Crime and Justice, v. 30, p. 283-357, 2003. p. 346). 


\section{CONCLUSÃo.}

"History reveals that strong beliefs in deterrence, particularly when combined with the moral or religious belief that sin should be punished, can produce results which later generations will consider unnecessarily brutal".

ANDENAES, Johannes.Punishment and deterrence. Ann Arbor: University of Michigan Press, 1974. p. 90.

A presente pesquisa foi iniciada com o propósito de trazer uma modesta contribuição ao estudo crítico, no Brasil, das promessas dissuasórias veiculadas pelo recrudescimento punitivo, procurando apontar o esgotamento de tal modelo.

1. Tendo-se apresentado as bases do fenômeno do neopunitivismo praticado no país a partir do período da redemocratização na década de 1980, e que veio a reboque de um movimento observado também nos países centrais do capitalismo, associado ao próprio neoliberalismo econômico - sendo, aqui, bastante atrelado a um populismo penal que marcou sobremaneira o enfoque do bandido como o novo inimigo social, desviando as atenções da população a respeito das verdadeiras mazelas de nossas estruturais desigualdade e disfuncionalidade social -, passou-se às discussões a respeito do poder dissuasório da ameaça penal, com apontamentos, inclusive calcados em investigações empíricas, focados inicialmente em países chamados centrais do capitalismo (com destaque à doutrina publicada na Europa e nos Estados Unidos da América) e, em seguida, empreendendo-se uma breve análise da política criminal praticada no Brasil, com destaque à Lei dos Crimes Hediondos e à chamada guerra às drogas.

2. As investigações demonstraram a impossibilidade de juízos categóricos acerca de um inerente e geral papel dissuasório da ameaça penal, especialmente no que toca à sua associação com o fenômeno do recrudescimento punitivo. E, antes até, as investigações também revelaram a grande dificuldade de se isolarem inúmeras variáveis capazes de interferir nas abordagens empíricas para se procurar estudar o fenômeno. Com isso, há ao menos significativa incerteza no sentido de qualquer promessa de redução ou contenção da criminalidade em razão de um recrudescimento penal.

3. A par das questões éticas imbricadas, fato é que a promessa dissuasória parece nunca ser vendida em conjunto com as evidências empíricas cientificamente embasadas capazes de atribuir ao menos certo ar de racionalidade às escolhas políticas. $\mathrm{O}$ 
recrudescimento permanece alheio a qualquer teste de idoneidade como política pública racional, fiel aos preceitos constitucionais da razoabilidade, proporcionalidade e vedação a penas cruéis, desumanas e degradantes. Como o enfoque que se procurou dar ao presente ensaio, para além do analítico, foi o crítico, não se furta a concluir pelo mais perfeito caráter simbólico de todo o recrudescimento punitivo observado no país, no período em análise, no que toca à promessa dissuasória. Se o encarceramento em massa, fruto das políticas públicas de recrudescimento com vistas à dissuasão, atende aos anseios de manutenção da imagem do criminoso no país, se ele contribui sobremaneira para que a roda do discurso do medo e da insegurança permaneça girando, se, ainda, garante, com isso, a manutenção de dispendiosos gastos públicos devidamente canalizados por determinados agentes econômicos e propicia o desenvolvimento da milionária economia da segurança privada, não tem ele, no entanto, propiciado a ampliação da adesão às normas em nossa sociedade. Com vistas à superação de tal paradigma dentro dos sistemas de justiça criminal e de segurança pública brasileiros é que se espera possa ter contribuído com o presente ensaio. Um passo seguinte seria perquirir a fundo as alternativas. Porém, não constituindo objeto da presente pesquisa tal investigação, empreendeu-se apenas uma breve análise a respeito do modelo que melhor parece ocupar o centro da linha condutora de uma política criminal de base verdadeiramente democrática, o da legitimidade e justeza procedimental. 


\section{BIBLIOGRAFIA.}

AlBRECHT, Hans-Jörg. Prison overcrowding - finding effective solutions: strategies and best practices against overcrowding in correctional facilities. Max Planck Institute for Foreign and International Criminal Law. Freiburg im Breisgau. 2012.

ANDENAES, Johannes. General prevention: illusion or reality? Journal of Criminal Law and Criminology, v. 43, n. 2, p. 176-198, 1952.

. The general preventive effects of punishment. University of Pennsylvania Law Review, v. 114, n. 7, p. 949-983, may 1966.

. Does punishment deter crime? The Criminal Law Quarterly, v. 11, p. 76-93, 19681969.

. The morality of deterrence. University of Chicago Law Review, v. 37, n. 4, p. 649$664,1970$.

. Punishment and deterrence. Ann Arbor: University of Michigan Press, 1974.

Andrade, Vera Regina Pereira de. Minimalismos, abolucionismos e eficienticismo: a crise do sistema penal entre a deslegitimação e a expansão. Revista Sequência, n. 52, p. 163-182, jul. 2006.

AnItUA, Gabriel Ignacio. Histórias dos pensamentos criminológicos. Tradução de Sérgio Lamarão. Rio de Janeiro: ICC/Revan, 2008.

ARENDT, Hannah. Eichmann em Jerusalém: um relato sobre a banalidade do mal. Tradução de José Rubens Siqueira. São Paulo: Companhia das Letras, 1999.

AshKaR, Peter J.; KenNy, Dianna T. Young offenders' subjective experiences of incarceration. International Journal of Offender Therapy and Comparative Criminology, v. 52, n. 5, p. 584-597, oct. 2008.

Bandeira de Mello, Celso Antônio. Curso de Direito Administrativo. 20. ed. São Paulo: Malheiros, 2005.

Baratta, Alessandro. Prefácio. In: BAtista, Vera Malaguti. Dificeis ganhos fáceis: droga e juventude pobre no Rio de Janeiro. 2. ed. Rio de Janeiro: ICC/Revan, 2003.

. Criminologia crítica e crítica do direito penal: introdução à sociologia do direito penal. Tradução de Juarez Cirino dos Santos. 6. ed. Rio de Janeiro: ICC/Revan, 2011. 
Barbosa, Danielle Rinaldi; SouzA, Thiago Santos de. Direito da criança e do adolescente: proteção, punição e garantismo. Curitiba: Juruá, 2013.

BATISTA, Vera Malaguti. Dificeis ganhos fáceis: droga e juventude pobre no Rio de Janeiro. 2. ed. Rio de Janeiro: ICC/Revan, 2003.

Bauman, Zygmunt. Comunidade: a busca por segurança no mundo atual. Tradução de PlínioDentzien. Rio de Janeiro: Zahar, 2003.

BECKER, Gary S. Crime and punishment: an economic approach. In: BECKER, Gary S.; LANDES, William M. (eds.). Essays in the economics of crime and punishment, 1974. p. 154.

BeCKetT, Katherine; WeStern, Bruce. Governing social marginality: welfare, incarceration, and the transformation of state policy. Punishment \& Society, v. 3, n. 1, p.4359, jan.2001.

Berdugo Gómez de La Torre, Ignacio; Arroyo Zapatero, Luis. Manual de derecho penal. I. Parte general: instrumentos y principios básicos del derecho penal. Barcelona: Editorial Praxis, 1994.

BitTNER, Egon; Platt, Anthony M. The meaning of punishment. Issues in Criminology, v. 2, n. 1, p. 79-99, 1966.

Blumstein, Alfred. Approaches to reducing both imprisonment and crime. Criminology \& Public Policy, v. 10, n. 1, p. 93-101, 2011.

Blumstein, Alfred; BeCK, Allen J. Population growth in U. S. prisons, 1980-1996. Crime and Justice, v. 26, p. 17-61, 1999.

BoITEUX, Luciana. Drogas e cárcere: repressão às drogas, aumento da população penitenciária brasileira e alternativas. In: SHECAIRA, Sérgio Salomão (Org.). Drogas: uma nova perspectiva. São Paulo: IBCCRIM, 2014. p. 83-103.

BragA, Anthony A. Getting deterrence right? Evaluation evidence and complementary crime control Mechanisms. Criminology \& Public Policy, v. 11, n. 2, p. 201-210, 2012.

Bushway, Shawn D.; Reuter, Peter. Deterrence, Economics, and the context of drug markets. Criminology \& Public Policy, v. 10, n. 1, p. 183-194, 2011.

Carvalho, Salo de. Em defesa da lei de responsabilidade político-criminal. Boletim IBCCRIM, São Paulo, v. 16, n. 193, p.8-9, dez. 2008. 
CAStro, Lola Aniyar de. Criminologia da reação social. Tradução e acréscimos de Ester Kosovski. Rio de Janeiro: Forense, 1983.

. Criminologia da libertação. Tradução de Sylvia Moretzsohn. Rio de Janeiro: ICC/Revan, 2005.

Chalfin, Aaron; Haviland, Amelia M.; , Steven. What do panel studies tell us about a deterrent effect of capital punishment? A critique of the literature. Journal of Quantitative Criminology, v. 29, n. 1, p. 5-43, 2013.

Christie, Nils. Civilidade e estado. Tradução de Beatriz Scigliano Carneiro. In: PASSETTI, Edson; DiAs DA SILva, Roberto Batista (Orgs.). Conversações abolicionistas: uma crítica do sistema penal e da sociedade punitiva. São Paulo: IBCCRIM, 1997.

. Uma razoável quantidade de crime. Tradução de André Nascimento. Rio de Janeiro: ICC/Revan, 2011.

CONRAD, John P. Deterrence, the death penalty, and the data. In: HAAG, Ernest van den; ConRAD, John P. The death penalty: a debate. New York: Plenum Publishing Corp., 1983. p. 133-156.

Conselho Federal de Psicologia; Conselho Federal da Ordem dos Advogados do BRASIL. Inspeção Nacional às unidades de internação de adolescentes em conflito com a lei: relatório das visitas realizadas simultaneamente em 22 estados brasileiros e no Distrito Federal, no dia 15 de março de 2006. 2. ed. Disponível em: http://site.cfp.org.br/wpcontent/uploads/2006/08/Direitos_Humanos_um_retrato_das_unidades_de_internacao_de_ adolescentes_em_conflito_com_a_lei.pdf. Acesso em: 10.01.2018.

CORCIOLi FilHO, Roberto. A corrupção do judiciário. Revista de Estudos Jurídicos UNESP, Franca, v. 17, n. 25, p. 433-474, jan.-jul. 2013.

. Criminologia do achismo. Boletim IBCCRIM, São Paulo, n. 253, p. 14-15, 2013.

. Voluntarismo judicial: a internação de adolescentes por tráfico de drogas no TJSP. Revista Brasileira de Ciências Criminais (no prelo).

Corcioli Filho, Roberto; Nunes, Plínio. O Brasil e a criminalização da pobreza. Trabalho apresentado em seminário na matéria do programa de pós-graduação (FADUSP - segundo semestre de 2015) Perspectivas Sociológicas e Clínica da Criminologia na Legislação Penal, sob responsabilidade dos professores Sergio Salomão Shecaira e Alvino Augusto de Sá. 
CymRot, Danilo. A relatividade do poder dissuasório da pena. Revista internacional de direito e cidadania, Erechim, v. 2, n. 5, p. 25-35, out. 2009.

Departamento Penitenciário Nacional. Ministério da Justiça. Levantamento Nacional de Informações Penitenciárias INFOPEN - junho de 2014. Disponível em: https://www.justica.gov.br/noticias/mj-divulgara-novo-relatorio-do-infopen-nesta-tercafeira/relatorio-depen-versao-web.pdf.Acessoem:10.01.2018.

Departamento Penitenciário Nacional. Ministério da Justiça. Levantamento Nacional de Informações Penitenciárias INFOPEN - dezembro de 2014. Disponível em: http://www.justica.gov.br/seus-direitos/politicapenal/infopen_dez14.pdf/@@download/file.Acessoem:10.01.2018.

DiChiara, Albert; GALLIHER, John F. Thirty years of deterrence research: characteristics, causes, and consequences. Contemporary Crises, v. 8, p. 243-263, 1984.

Dieter, Maurício Stegemann. Política Criminal Atuarial: a criminologia do fim da história. Rio de Janeiro: Revan, 2013.

DöLling, Dieter; ENTORF, Horst; HERMANN, Dieter; RuPP, Thomas. Is deterrence effective? Results of a meta-analysis of punishment. European Journal on Criminal Policy and Research, v. 15, p. 201-224, 2009.

Durlauf, Steven N.; Fu, Chao; NAVArro, Salvador. Capital punishment and deterrence: understanding disparate results. Journal of Quantitative Criminology, v. 29, n. 1, p. 103-121, 2013.

Durlauf, Steven N.; NAgin, Daniel S. Imprisonment and crime - can both be reduced? Criminology \& Public Policy, v. 10, n. 1, p. 13-54, 2011.

Ferrajoli, Luigi. Direito e razão. Tradução de Ana Paula Zomer Sica; Fauzi Hassan Choukr; Juarez Tavares; Luiz Flávio Gomes. 2. ed. São Paulo: Revista dos Tribunais, 2006. FOLHA DE SÃo PAULO. Infrações por uso de celular caem com multa mais alta em São Paulo, 11.04.2017. Disponível em: http://www1.folha.uol.com.br/cotidiano/2017/04/1874530infracoes-por-uso-de-celular-caem-com-multa-mais-alta-em-sao-paulo.shtml. Acesso em: 10.01.2018.

Fórum Brasileiro de Segurança PúblicA. Anuário Brasileiro de Segurança Pública 2014.

em: 
http://www.forumseguranca.org.br/storage/8_anuario_2014_20150309.pdf. Acesso em: 10.01.2018.

. Audiência de Custódia, Prisão Provisória e Medidas Cautelares: Obstáculos Institucionais e Ideológicos à Efetivação da Liberdade como Regra. 2017. Disponível em: http://www.cnj.jus.br/noticias/cnj/85593-audiencias-de-custodia-maioria-saojovens.Acessoem: 10.01.2018.

FouCAUlt, Michael. Vigiar e punir. Tradução de Raquel Ramalhete.40. ed. Petrópolis: Vozes, 2012.

Franco, Alberto Silva. Prefácio. In: KARAM, Maria Lúcia. Juizados especiais criminais: a concretização antecipada do poder de punir. São Paulo: Revista dos Tribunais, 2004.

. Crimes hediondos. 6. ed. São Paulo: Revista dos Tribunais, 2007.

. Na expectativa de um novo paradigma. In: ANDRADE, Manuel da Costa; ANTUNES, Maria João; SouSA, Susana Aires de (Coord.). Estudos em homenagem ao prof. doutor Jorge de Figueiredo Dias. Volume I. Coimbra: Coimbra, 2009. p. 323-346.

FREUD, Sigmund. Criminoso em conseqüência de um sentimento de culpa. In: . A história do movimento psicanalítico. Artigos sobre metapsicologia e outros trabalhos. Volume XIV das obras psicológicas completas do autor. Tradução sob a direção-geral de Jayme Salomão. Rio de Janeiro: Imago, 1974. p. 375-377.

GARLAND, David. As contradições da "sociedade punitiva": o caso britânico. Revista de Sociologia e Politica, Curitiba, n. 13, p. 59-80, nov. 1999. . A cultura do controle: crime e ordem social na sociedade contemporânea. Tradução de André Nascimento. Rio de Janeiro: ICC/Revan, 2008.

Giorgi, Alessandro De. A miséria governada através do sistema penal. Tradução de Sérgio Lamarão. Rio de Janeiro: Revan, 2006.

GneEzy Uri; Rustichini, Aldo. A fine is a price. The Journal of Legal Studies, The University of Chicago, v. 29, p. 1-17, jan. 2000.

GoMES, Marcus Alan de Melo. Mídia, poder e delinquência. Boletim IBCCRIM, São Paulo, n. 238, p. 4-5, 2012.

Gomes, Mariângela Gama de Magalhães. O princípio da proporcionalidade penal. São Paulo: Revista dos Tribunais, 2003. 
GREENBERG, David F. Introduction. In: (Ed.). Crime and capitalism: readings in marxist criminology. 2. ed. Philadelphia: Temple University Press. 1993. p. 1-35.

HART, Carl. Um preço muito alto: a jornada de um neurocientista que desafia nossa visão sobre as drogas. Tradução de Clóvis Marques. Zahar: Rio de Janeiro, 2014.

HASSEMER, Winfrid. Sobre a consideração das conseqüências na interpretação da lei penal. Tradução de Mariana Ribeiro de Souza, revista por Carlos Eduardo de Oliveira Vasconcelos. In: Vasconcelos, Carlos Eduardo de Oliveira (Org.). Direito penal: fundamentos, estrutura, política. Porto Alegre: Sergio Antonio Fabris, 2008. p. 129-169.

Hillyard, Paddy; Tombs, Steve. Beyond criminology? In: Hillyard, Paddy; PAnTAZis, Christina; TomBS, Steve; Gordon, Dave. Beyond Criminology: taking harm seriously. London: Pluto Press, 2004. p. 10-29.

Homel, Ross. Policing and punishing the drinking driver - A study of general and specific deterrence. New York: Springer, 1988.

Hulsman, Louk. Descriminalização. Revista de Direito Penal, Rio de Janeiro, n. 9/10, p. 726, jan.-jun. 1973.

. Temas e conceitos numa abordagem abolicionista da justiça criminal. Tradução de Maria Abramo Brant de Carvalho. In: PASSETTI, Edson; DiAS DA SILVA, Roberto Batista (Orgs.). Conversações abolicionistas: uma crítica do sistema penal e da sociedade punitiva. São Paulo: IBCCRIM, 1997.

InSTITUTO BRASILEIRO DE CIÊNCIAS CRIMINAIS (IBCCRIM). Visões de política criminal entre operadores da justiça criminal de São Paulo: relatório de pesquisa. São Paulo: Revista dos Tribunais, 2007.

. Boletim n. 277. Ano 23, dezembro/2015.

Instituto Brasileiro de Geografia e Estatística (IBGE). Pesquisa Nacional por Amostra de Domicílios (Pnad). Disponível em: https://ww2.ibge.gov.br/home/estatistica/populacao/trabalhoerendimento/pnad2014/default .shtm. Acesso em: 10.01.2018.

Jackson, Jonathan; Bradford, Ben; Hough, Mike; Myhill, Andy; Quinton, Paul; TYLER, Tom R. Why do people comply with the law? Legitimacy and the Influence of Legal Institutions. The British Journal of Criminology, v. 52, n. 6, p. 1051-1071, 2012. Versão 
consultada disponível em: http://ssrn.com/abstract=1994490(p. 1-22). Acesso em: 10.01.2018.

JiAnG, Shanhe; LAMBERT, Eric G.; WANG, Jin. Capital punishment views in China and the United States. International Journal of Offender Therapy and Comparative Criminology, v. 51, n. 1, p. 84-97, 2007.

KAHN, Tulio. Intimidação, incapacitação ou prevenção? Qual o melhor meio para reduzir a criminalidade. Revista brasileira de ciências criminais, São Paulo, n. 81, p. 197-206, abr.jun. 2000.

. Crescimento econômico e criminalidade: uma interpretação da queda dos crimes no Sudeste e aumento no Norte/Nordeste. Revista Brasileira de Segurança Pública, São Paulo, v. 7, n. 1, fev.-mar. 2013.

KARAM, Maria Lúcia. A esquerda punitiva. Discursos sediciosos: crime, direito e sociedade, Rio de Janeiro, n. 1, p.79-92, 1996.

Utopia transformadora e abolição do sistema penal. In: PASSETTI, Edson; DIAS DA Silva, Roberto Batista (Orgs.). Conversações abolicionistas: uma crítica do sistema penal e da sociedade punitiva. São Paulo: IBCCRIM, 1997.

. Juizados especiais criminais: a concretização antecipada do poder de punir. São Paulo: Revista dos Tribunais, 2004.

Killias, Martin; Scheidegger, David; Nordenson, Peter. The effects of increasing the certainty of punishment: a field experiment on public transportation. European Journal of Criminology, v. 6, n. 5, p. 387-400, 2009.

Kovandzic, Tomislav V.; SloAN III, John J.; Vieraitis, Lynne M. Unintended consequences of politically popular sentencing policy: the homicide promoting effects of "three strikes" in U.S. cities (1980-1999). Criminology \& Public Policy, v. 1, n. 3, p. 399424, 2002.

Kovandzic, Tomislav V.; VIERAITIS, Lynne M. The effect of county-level prison population growth on crime rates. Criminology \& Public Policy, v. 5, n. 2, p. 213-244, 2006.

Kovandzic, Tomislav V.; Vieraitis, Lynne M.; Boots, Denise Paquette. Does the death penalty save lives? New evidence from state panel data, 1977 to 2006. Criminology \& Public Policy, v. 8, n. 4, p. 803-843, 2009. 
Lima, Renato Sérgio de; Bueno, Samira (Coord.). $7^{\circ}$ Anuário Brasileiro de Segurança Pública. São $\quad 2013 . \quad$ Paulo, Disponível em: http://www.forumseguranca.org.br/storage/7_anuario_2013-corrigido.pdf. Acesso em: 10.01.2018.

MARREY, Luiz Antonio Guimarães. Guarda Municipal não é polícia. In: Folha de S. Paulo. 05.07.2016. A3.

MATHIESEn, Thomas. A caminho do século XXI: abolição, um sonho impossível? Tradução de Jamil Chade. In: PASSETTI, Edson; DiAs DA Silva, Roberto Batista (Orgs.). Conversações abolicionistas: uma crítica do sistema penal e da sociedade punitiva. São Paulo: IBCCRIM, 1997.

Melossi, Dario; PAVARInI, Massimo. Cárcere e fábrica: as origens do sistema penitenciário (século XVI-XIX). Tradução de Sérgio Lamarão. 2. ed. Rio de Janeiro: ICC/Revan, 2010.

Minahim, Maria Auxiliadora de Almeida; Sposato, Karyna Batista. A internação de adolescentes pela lente dos tribunais. Revista direito GV, São Paulo, v. 7, n. 1, p. 277-298, jan./jun. 2011.

Ministério PÚblico do Estado de São PaUlo. Relatório Cômputo do Estado de São Paulo. Disponível

em: http://www.mpsp.mp.br/portal/page/portal/home/banco_imagens/flash/RelatorioDiagnostic o2012/rdmp50.pdf. Acesso em:10.01.2018.

Ministério PÚBlico Federal. Campanha “10 Medidas Contra a Corrupção”. Disponível em: http://www.dezmedidas.mpf.mp.br/. Acesso em:10.01.2018.

MuÑoz, Alberto Alonso. Eichmann em Jerusalém e a banalidade do mal na decisão do juiz. Jornal da Associação Juízes para a Democracia, São Paulo, n. 52, p. 6-7, jan./mar. 2011.

MurPhy, Jeffrie G. Marxism and retribution. In: TONRY, Michael (Ed.). Why punish? How much? A reader on punishment. New York: Oxford University Press. 2011. p. 127-145.

Nascimento, André. Prefácio. In: Garland, David. A cultura do controle: crime e ordem social na sociedade contemporânea. Tradução de André Nascimento. Rio de Janeiro: Revan, 2008 .

Nellis, Ashley. The Color of Justice: Racial and Ethnic Disparity in State Prisons. The SentencingProject,2016. Disponível em: http://www.sentencingproject.org/wp- 
content/uploads/2016/06/The-Color-of-Justice-Racial-and-Ethnic-Disparity-in-StatePrisons.pdf. Acesso em:10.01.2018.

NeLson, Douglas W. A road map for juvenile justice reform. In: Kids Count Data Book. Baltimore: Annie E. Casey Foundation, 2008.p. 6-27. Disponível em: http://www.aecf.org/resources/the-2008-kids-count-data-book/. Acesso em: 10.01.2018.

OliveirA, Luciano. Não Fale do Código de Hamurábi! A pesquisa sócio-jurídica na pós graduação em Direito. Anuário dos Cursos de Pós- Graduação em Direito (UFPE), v. 13, p. 299-330, 2003.

PaIVA, Luiz Guilherme Mendes de. Populismo penal no Brasil: do modernismo ao antimodernismo penal, 1984-1990. Tese de Doutorado. Faculdade de Direito, Universidade de São Paulo. São Paulo, 2014.

PASTANA, Débora Regina. Justiça penal no Brasil contemporâneo: discurso democrático, prática autoritária. São Paulo: Unesp, 2009.

PAULA, Liana de. A distância entre o ECA e o sistema socioeducativo no Brasil. In: LiMA, Renato Sérgio de; BuEno, Samira (Coord.). $7^{\circ}$ Anuário Brasileiro de Segurança Pública. São Paulo, 2013. p. 88. Disponível em: http://www.forumseguranca.org.br/storage/7_anuario_2013-corrigido.pdf. Acesso em: 10.01.2018.

PAVARINI, Massimo. El grotesco de la penología contemporánea. Revista brasileira de ciências criminais, São Paulo, v. 17, n. 81, p. 230-279, nov./dez. 2009.

Perelman, Chaïm. Ética e Direito. Tradução de Maria Ermantina de Almeida Prado Galvão. 2. ed. São Paulo: Martins Fontes, 2005.

PIRES, Álvaro. La politique législative et les crimes à "double face”: Éléments pour une théorie pluridimentionnelle de la loi criminelle (Drogues, prostitution, etc.). Rapport d'expert à l'intention du Comité spécial du Sénat du Canada sur les drogues illicites. 2002. Disponível em: http:/www.parl.gc.ca/content/sen/committee/371/ille/presentation/piresf.htm. Acesso em:10.01.2018.

PogARSKY, Greg. Deterrence and decision making: research questions and theoretical refinements. In: Krohn, Marvin D.; LizotTe, Alan J.; Hall, Gina Penly (Eds.). Handbook on Crime and Deviance. New York: Springer, 2009. p. 241-258. 
PonTEll, Henry N. Deterrence: theory versus practice. Criminology, v. 16, n. 1, p. 3-22, may 1978.

Posner, Richard A. A economia da justiça. Tradução de Evandro Ferreira e Silva. São Paulo: WMF Martins Fontes, 2010.

Prado, Lídia Reis de Almeida. O Juiz e a emoção: aspectos lógicos da decisão judicial. 4. ed. Campinas: Millennium, 2008.

QuinNEY, Richard. Classe, Estado e crime. Tradução de Gustavo de Souza Preussler, Jaume Aran, Larissa de Araújo Montes. Curitiba: Íthala, 2016.

Roxin, Claus. Sentido e limites da pena estatal. In: . Problemas fundamentais de direito penal. Tradução de Ana Paula dos Santos e Luís Natscheradetz. Lisboa: Vega, 1998. p. $15-47$.

Rubin, Paul H. Don't scrap the death penalty. Criminology \& Public Policy, v. 8, n. 4, p. 853-859, 2009.

Rusche, Georg; KIRChHeIMER, Otto. Punição e estrutura social. Tradução de Gizlene Neder.2. ed. Rio de Janeiro: ICC/Revan, 2004.

SÁ, Alvino Augusto. Criminologia clínica e psicologia criminal. São Paulo: Revista dos Tribunais, 2007.

SAMPSON, Robert J. The incarceration ledger: toward a new era in assessing societal consequences. Criminology \& Public Policy, v. 10, n. 3, p. 819-828, 2011.

SAntos, Cláudia Maria Cruz. O crime de colarinho branco - da origem do conceito e sua relevância criminológica à questão da desigualdade na administração da justiça penal. Coimbra: Coimbra, 2001.

SAntos, Juarez Cirino dos. A criminologia radical. Rio de Janeiro: Forense, 1981. . O adolescente infrator e os direitos humanos. Revista do Instituto Brasileiro de Direitos Humanos, v. 2, n. 2, p. 90-99, 2001.

SARAIVA, João Batista Costa. Medidas socioeducativas e o adolescente infrator. Revista da AJURIS, Porto Alegre, n. 78, p. 124-138, jun. 2000.

SCHEERER, Sebastian. Um desafio para o abolicionismo. Tradução de Beatriz Scigliano Carneiro. In: PASSETTI, Edson; DiAS DA Silva, Roberto Batista (Orgs.). Conversações 
abolicionistas: uma crítica do sistema penal e da sociedade punitiva. São Paulo: IBCCRIM, 1997.

SCHUMANN, Karl F.; KAULITZKI, Reiner. Limits of general deterrence: the case of juvenile delinquency. In: SeSSAR, Klaus; Kerner, Hans-Jürgen (Eds.). Developments in crime and crime control research. Research in Criminology. New York: Springer, 1991. p. 1-21.

SheCAIRA, Sérgio Salomão. Prisões do futuro? Prisões no futuro? In: PASSETTI, Edson; Dias DA Silva, Roberto Batista (Orgs.). Conversações abolicionistas: uma crítica do sistema penal e da sociedade punitiva. São Paulo: IBCCRIM, 1997.

. Criminologia. 2. ed. São Paulo: Revista dos Tribunais, 2008.

_ Criminologia: um estudo das escolas sociológicas. São Paulo: Estúdio Editores, 2014.

Shecaira, Sérgio Salomão; Franco, Alberto Silva; LiRA, Rafael de Souza. Lei de responsabilidade política. Boletim IBCCRIM, São Paulo, v. 24, n. 289, p. 2-4, dez. 2016.

SHEPHERD, Joanna. The imprisonment puzzle: understanding how prison growth affects crime. Criminology \& Public Policy, v. 5, n. 2, p. 285-298, 2006.

SHEPHERD, Jonathan P. Criminal deterrence as a public health strategy. The Lancet, v. 358, p. $1717-1722,2001$.

Sinhoretto, Jacqueline; BAtitucci, Eduardo; MotA, Fábio Reis; Schlittler, Maria Carolina; Silvestre, Giane; MoraIs, Danilo de Souza; SouzA, Letícia Godinho de; SousA, Rosânia Rodrigues de; Silva, Sabrina Souza da; Ovalle, Luiza Aragon; RAmos, Paulo César; AlmeidA, Fabrício Bonecini de; MACIEL, Welliton Caixeta. A filtragem racial na seleção policial de suspeitos: segurança pública e relações raciais. In: LIMA, Cristiane do Socorro Loureiro; BAPTISTA, Gustavo Camilo; Figueiredo, Isabel Seixas de (Org.). Segurança pública e direitos humanos: temas transversais. Brasília: Ministério da Justiça, 2014, v. 5, p. 121-158.

SinHORETTO, Jacqueline; LiMA, Renato Sérgio de. Narrativa autoritária e pressões democráticas na segurança pública e no controle do crime. Contemporânea, v. 5, n. 1, p. 119-141, jan.-jun. 2015.

SKOLNICK, Jerome H. What not to do about crime - The American Society of Criminology 1994 Presidential Address. Criminology, v. 33, n. 1, p. 1-15, 1995. 
SMIT, Dirk van Zyl; ASHwORTH, Andrew. Disproportionate sentences as human rights violations. Modern Law Review, v. 67, n. 4, p. 541-560, jul. 2004.

SouZA, Jessé. A quem serve a classe média indignada? [10.01.2016]. São Paulo: Folha de São Paulo. Entrevista concedida a Marcelo Coelho. Disponível em: http://www1.folha.uol.com.br/ilustrissima/2016/01/1727369-a-quem-serve-a-classe-mediaindignada.shtml. Acesso em:10.01.2018.

Sutherland, Edwin H. El delito de cuello blanco. Tradução de Rosa del Olmo. Caracas: Universidad Central de Venezuela, 1969.

TONRY, Michael. Less imprisonment is no doubt a good thing- more policing is not. Criminology \& Public Policy, v. 10, n. 1, p. 137-152, 2011.

TYLER, Tom R. Procedural justice, legitimacy and the effective rule of law. Crime and Justice, v. 30, p.283-357, 2003.

. Legitimacy and criminal justice: the benefits of self-regulation. Ohio State Journal of Criminology Law, v. 7, p. 307-358, 2009.

. Why people obey the law. Princeton University Press: Princeton, 2006.

WACQuAnt, Loïc. Punir os pobres: a nova gestão da miséria nos Estados Unidos[ A onda punitiva]. Tradução de Sérgio Lamarão. 3. ed. Rio de Janeiro: Revan, 2007.

. As prisões da miséria. Tradução de André Telles. 2.ed. Rio de Janeiro: Zahar, 2011.

WaISElfiSz, Julio Jacobo. Mapa $d a$ violência 2013. Disponível em: http://www.mapadaviolencia.org.br/pdf2013/mapa2013_homicidios_juventude.pdf. Acesso em: 10.01.2018.

WiKSTRÖM, Per-Olof H.; SVENSSON, Robert.When does self-control matter? The interaction between morality and self-control in crime causation. European Journal of Criminology, v. 7, n. 5, p. 395-410, 2010.

WiKström, Per-Olof; TSElOnI, Andromachi; KARLIS, Dimitris. Do people comply with the law because they fear getting caught? European Journal of Criminology, v. 8, n. 5, p. 401420, 2011.

WiLKInSON, Richard; PICKETT, Kate. The spirit level: why greater equality makes societies stronger. New York: Bloomsbury Press, 2010. 
YounG, Jock. A sociedade excludente: exclusão social, criminalidade e diferença da modernidade recente. Tradução de Renato Aguiar. Rio de Janeiro: ICC/Revan, 2002.

ZAFFARONI, Eugenio Raúl. Poder judiciário: crise, acertos e desacertos. Tradução de Juarez Tavares. São Paulo: Revista dos Tribunais, 1995.

. La globalización y las actuales orientaciones de la política criminal. Direito e Cidadania, Praia, Cabo Verde, v. 3, n. 8, p. 71-94, nov./fev. 1999/2000.

. O inimigo no direito penal. Tradução de Sérgio Lamarão. 2. ed. Rio de Janeiro: ICC/Revan, 2007.

Zanetic, André; Manso, Bruno Paes; NAtal, Ariadne Lima; Oliveira, Thiago Rodrigues. Legitimidade da polícia: segurança pública para além da dissuasão. Civitas, Porto Alegre, v. 16, n. 4, p. 148-173, out.-dez. 2016 


\section{ANEXo De TABELAS}

Evolução do delito de homicídio doloso (inclusive na forma tentada) de 1991 a 2003:

\begin{tabular}{|l|l|}
\hline Ano & Homicídios dolosos \\
\hline 1991 & 8.368 \\
\hline 1992 & 7.480 \\
\hline 1993 & 8.436 \\
\hline 1994 & 9.650 \\
\hline 1995 & 10.663 \\
\hline 1996 & 11.830 \\
\hline 1997 & 11.791 \\
\hline 1998 & 12.711 \\
\hline 1999 & 13.978 \\
\hline 2000 & 13.698 \\
\hline 2001 & 12.360 \\
\hline & \\
\hline & \\
\hline & 12.966 \\
\hline & \\
\hline & \\
\hline & \\
\hline
\end{tabular}

Evolução do delito de tráfico de 1991 a 2003:

\begin{tabular}{|l|l|}
\hline Ano & Tráfico \\
\hline 1991 & 1.307 \\
\hline
\end{tabular}




\begin{tabular}{|l|l|}
\hline 1992 & 1.459 \\
\hline 1993 & 1.588 \\
\hline 1994 & 1.564 \\
\hline 1995 & 1.804 \\
\hline 1996 & 2.027 \\
\hline 1997 & 2.224 \\
\hline 1998 & 2.601 \\
\hline 1999 & 2.573 \\
\hline 2000 & 2.154 \\
\hline 2001 & 2.491 \\
\hline 2002 & 3.300 \\
\hline & 3.924 \\
\hline
\end{tabular}


Evolução dos delitos de latrocínio, extorsão mediante sequestro, extorsão, estupro (apenas consumado, de 1986 1990, e em ambas as formas nos anos seguintes) e atentado violento ao pudor, de 1986 a 2003:

\begin{tabular}{|c|c|c|c|c|c|}
\hline Ano & Latrocínio & $\begin{array}{l}\text { Extorsão } \\
\text { mediante } \\
\text { sequestro }\end{array}$ & Extorsão & Estupro & $\begin{array}{l}\text { Atentado } \\
\text { violento } \\
\text { ao pudor }\end{array}$ \\
\hline 1986 & 266 & 95 & 251 & 2.024 & 813 \\
\hline 1987 & 231 & 99 & 394 & 1.894 & 946 \\
\hline 1988 & 273 & 78 & 244 & 1.817 & 942 \\
\hline 1989 & 381 & 81 & 261 & 1.815 & 1.113 \\
\hline 1990 & 442 & 91 & 304 & 1.852 & 1.204 \\
\hline 1991 & 474 & 80 & 374 & 2.702 & 1.264 \\
\hline 1992 & 434 & 72 & 579 & 2.607 & 1.396 \\
\hline 1993 & 333 & 67 & 493 & 2.550 & 1.541 \\
\hline 1994 & 336 & 70 & 303 & 2.735 & 1.631 \\
\hline 1995 & 319 & 63 & 288 & 2.587 & 1.466 \\
\hline 1996 & 390 & 61 & 339 & 2.302 & 1.378 \\
\hline 1997 & 307 & 98 & 294 & 2.322 & 1.398 \\
\hline 1998 & 380 & 110 & 469 & 2.483 & 1.506 \\
\hline 1999 & 526 & 135 & 581 & 2.561 & 1.625 \\
\hline 2000 & 479 & 150 & 516 & 2.570 & 1.619 \\
\hline 2001 & 425 & 316 & 500 & 2.529 & 1.668 \\
\hline
\end{tabular}




\begin{tabular}{|l|l|l|l|l|l|}
\hline 2002 & 306 & 306 & 676 & 2.560 & 2.023 \\
\hline 2003 & 305 & 199 & 690 & 2.500 & 2.247 \\
\hline
\end{tabular}


Evolução da população carcerária brasileira (em mil) de 1990 a 2014:

\begin{tabular}{|c|c|}
\hline Ano & População carcerária \\
\hline 1990 & 90,0 \\
\hline 1992 & 114,3 \\
\hline 1993 & 126,2 \\
\hline 1994 & 129,2 \\
\hline 1995 & 148,8 \\
\hline 1997 & 170,6 \\
\hline 1999 & 194,1 \\
\hline 2000 & 232,8 \\
\hline 2001 & 233,9 \\
\hline 2002 & 239,3 \\
\hline 2003 & 308,3 \\
\hline 2004 & 336,4 \\
\hline 2005 & 361,4 \\
\hline 2006 & 401,2 \\
\hline 2007 & 422,4 \\
\hline 2008 & 429,4 \\
\hline 2009 & 473,6 \\
\hline 2010 & 496,3 \\
\hline 2011 & 514,6 \\
\hline
\end{tabular}




\begin{tabular}{|l|l|}
\hline 2012 & 549,8 \\
\hline 2013 & 581,5 \\
\hline 2014 & 622,2 \\
\hline
\end{tabular}

Denúncias por tráfico de drogas pelo Ministério Público do Estado de São Paulo, de 2004 a 2011:

\begin{tabular}{|l|l|l|l|l|l|l|l|}
\hline $\mathbf{2 0 0 4}$ & $\mathbf{2 0 0 5}$ & $\mathbf{2 0 0 6}$ & $\mathbf{2 0 0 7}$ & $\mathbf{2 0 0 8}$ & $\mathbf{2 0 0 9}$ & $\mathbf{2 0 1 0}$ & $\mathbf{2 0 1 1}$ \\
\hline 11.123 & 12.630 & 13.728 & 17.929 & 19.546 & 20.976 & 21.799 & 22.936 \\
\hline
\end{tabular}

